\title{
In vivo Efficacy of HIFU (High Intensity Focused Ultrasound) on Mice with Ehrlich Ascites Carcinoma
}

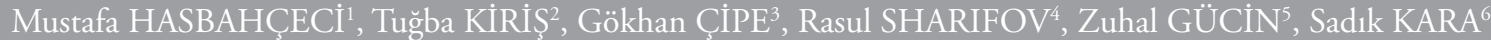 \\ Öykü ONARAN ${ }^{7}$, Mahmut MÜSLÜMANOĞLU ${ }^{8}$ \\ 'Department of General Surgery, Bezmialem Vakif University, School of Medicine, İstanbul, Turkey \\ 'İstanbul University, Institute of Graduate Studies in Natural and Applied Sciences, İstanbul, Turkey \\ ${ }^{3}$ Medicana International Hospital, İstanbul, Turkey \\ ${ }^{4}$ Department of Radiology, Bezmialem Vakif University, School of Medicine, İstanbul, Turkey \\ ${ }^{5}$ Department of Pathology, Bezmialem Vakif University, School of Medicine, İstanbul, Turkey \\ ${ }^{6}$ Retired Faculty Member, İstanbul, Turkey \\ ${ }^{7}$ Medical Faculty Student, İstanbul University Cerrahpaşa School of Medicine, İstanbul, Turkey \\ ${ }^{8}$ Department of General Surgery, İstanbul University, İstanbul School of Medicine, İstanbul, Turkey
}

\section{ABSTRACT}

Objective: Cavitation and coagulation necrosis due to high temperature caused by application of the high intensity focused ultrasound (HIFU) to a focal area occurs. This feature makes HIFU possible to use in the destruction of cancerous tissue. In this study, it was aimed to determine the effect of HIFU on Balb/c mice with Ehrlich ascites tumor model to reach effective usage of HIFU with its clinical and experimental applications in various types of cancer.

Methods: Ehrlich ascites tumor cells were obtained from the intraperitoneal region of a donor mouse. Fresh ehrlich ascites tumor cells were injected into 24 mice that were randomly distributed after tumor formation as a control (Group 1), sham treatment (Group 2) and HIFU treatment (Group 3). HIFU application was performed under ultrasound image until conversion of the hypoechoic tumor tissues to hyperechoic appearances. Tumor size and volumes were measured

Results: Tumor sizes and volumes in all groups showed an increase after the treatment. Pathologically all tumors were solid carcinoma with an expansive growth pattern. Necrosis percentages in Group 1, Group 2 and Group 3 were 70 $\pm 9.6,70 \pm 9.4$ and 75.6 \pm 4.17 , respectively. With regard to Volume 2, there were significant differences between Group 2 and both Group 1 and 3 ( $p=0.004$ and $p=0.0001$, respectively).

Concluison: High intensity focused ultrasound is an effective method in Ehrlich ascites tumor model via prevention of tumor growth and production of necrosis. To achieve a reduction in tumor volume, increasing the duration of HIFU treatment and/or repeatedly application of the treatment is thought to be effective.

Keywords: High intensity focused ultrasound, Ehrlich ascites carcinoma, balb/c mice, cancer

\section{Introduction}

The mechanism of action of high-intensity focused ultrasonography (HIFU) is coagulation necrosis and cavitation that is caused by high heat resulting from high-energy and low-frequency ultrasound (USG) waves applied in a small focal area. The externally applied HIFU produces cigar-shaped ablation zones in the tissues reaching the focal length area of the USG waves without any effect on the skin (3). The formation of cavitation increases the size of air droplets. The increase in temperature as well as large stress pressures with explosion and rupture are observed (2). It is sufficient to raise the live tissue temperature above $56^{\circ} \mathrm{C}$ in $1 \mathrm{~s}$ for rapid cell death depending on coagulation necrosis, and the increases in temperature up to $80^{\circ} \mathrm{C}-90^{\circ} \mathrm{C}$ in the tissues are observed with $\operatorname{HIFU}(1,4)$. These pathological events are lethal for cells, and therefore they are used for the destruction of cancerous tissues.

Cite this article as: Hasbahçeci M, Kiriş T, Çipe G, Sharifov R, Gücin Z, Kara S, et al. In vivo Efficacy of HIFU (High Intensity Focused Ultrasound) on Mice with Ehrlich Ascites Carcinoma. Bezmialem Science 2017; 5: 168-74.

\begin{tabular}{|c|c|c|}
\hline $\begin{array}{l}\text { Address for Correspondence: Mustafa Hasbahçeci; Genel Cerrahi Anabilim Dalı, Bezmialem Vakif Üniversitesi Tıp } \\
\text { Fakültesi, İstanbul, Türkiye E-mail: hasbahceci@yahoo.com }\end{array}$ & $\begin{array}{l}\text { Received } \\
\text { Accepted }\end{array}$ & $\begin{array}{l}: 21.03 .2016 \\
: 24.10 .2016\end{array}$ \\
\hline
\end{tabular}


In recent years, HIFU has been used in the treatment of many benign and malignant diseases. The use of HIFU has become increasingly common because of the improvements in focusing and treatment time in the development process of the technique (1). It was transrectally used at a frequency of $3 \mathrm{MHz}$ in the treatment of patients with locally advanced prostate cancer, and successful results were reported (5). In a study conducted by Maestroni et al., 84\% success rate with the local control of prostate cancer was achieved. Blana et al. demonstrated that treatment with HIFU provided a $66 \%$ disease-free survival in patients with prostate cancer (6). Post-procedural pathological examinations also revealed that coagulation necrosis developed in patients with breast cancer who were treated with $\operatorname{HIFU}(7,8)$. Studies have demonstrated that HIFU is effective on hepatocellular carcinoma, renal cell carcinoma, benign thyroid nodules, uterine myomas, and locally advanced rectum and pancreatic cancers $(1,9-13)$.

A limited number of experimental studies have been performed in animal models with colon and pancreatic cancer to evaluate the efficacy of HIFU in various types of cancer and to obtain technical data on its clinical application $(2,14)$. HIFU, which has widespread clinical use in the non-surgical treatment of early prostate cancer, warrants more experimental studies to find an application area in gastrointestinal system cancers.

There is a limited number of experimental studies in which therapeutic USG was used in Ehrlich acid tumor model (1517). It has been shown that an increase in permeability with cell membrane damage caused by cutting force and oxygen radicals occurs, and the resulting acoustic cavitation inhibits tumor development (16). Although experimental studies have demonstrated that USG enhances the effectiveness of chemotherapeutic agents, the effect of therapeutic USG alone on the Ehrlich acid model has not been studied $(15,17)$.

In this study, we aimed to determine the effect of HIFU using the Ehrlich acid tumor model established in Balb/c mice.

\section{Methods}

The study was approved by the Local Ethics Committee of Experimental Animal Experiments of the Bezmialem Foundation University with the project number 2013/205. Experimental animals were obtained from the Bezmialem Foundation University Scientific Research Center Laboratory and were monitored during the experiment in the same laboratory at $23^{\circ} \mathrm{C}$ and in a 12 -h day-night cycle. Twenty-four male $\mathrm{Balb} / \mathrm{c}$ mice weighing 25-30 $\mathrm{g}$ and aged 5-7 weeks were used in the study.

To obtain Ehrlich tumor cell, $1 \mathrm{ml}$ containing approximately $1.5^{\prime} 10^{7}$ Ehrlich acid tumor cells were injected into the peritoneal cavity of the donor mice (Figure 1-a). Every four days, it was observed to check whether or not swelling occurred in the abdominal region. The acidic fluid comprising Ehrlich acid tumor cells was taken from the donor mouse with abdominal swelling at the end of the days 7-10 (Figure 1-b), and $0.5 \mathrm{ml}$ containing approximately $1.5 \times 10^{5}$ tumor cells were subcutaneously injected into the left-side region of the mice in the experimental group. The animals in which swelling and redness started to develop at the injection sites within 7-10 days following the inoculation were included in the study after their tumor size, measured with digital caliper, reached 5-6 $\mathrm{mm}$ (tumor diameter, approximately $1 \mathrm{~cm}^{3}$ ) after an average of 2-3 weeks (Figure 2).

When the tumor diameter reached 5-6 $\mathrm{mm}$, the tumor volume was measured with USG (frequency, 3.5 MHz).

A total of 24 randomly selected experimental animals, 8 in each group, were used in the study. Groups were determined as control (Group 1), sham treatment (Group 2), and HIFU treatment (Group 3).

\section{Group 1: Control Group}

In this group, mass formation was observed after tumor injection, and no intervention was performed for the diagnosis and treatment afterwards.

\section{Group 2: Sham Treatment Group}

After tumor cell injection, only diagnostic USG (frequency, $3.5 \mathrm{MHz}$ ) was performed.

\section{Group 3: HIFU Treatment Group}

Prior the procedure, the subjects were anesthetized with intraperitoneal ketamine hydrochloride $(35 \mathrm{mg} / \mathrm{kg}$; Ketalar, Pfizer, NY, USA) and 2\% xylazine (5 mg/kg; Rompun', Bayer, Leverkusen, Germany). The doses were repeated when necessary. After sufficient sedation was achieved, the area was trimmed, and protective gel was applied to prevent air between the probe and subject. Subsequently, subjects were laid in a lateral decubitus position and HIFU application (frequency, 1.5 MHz; Wuxi Haiying Techonology, China) was carried out under USG image for $1000 \mathrm{~ms}$ in every $10 \mathrm{~s}$ until hypoechoic tumor tissue became hyperechoic (Figure 3).

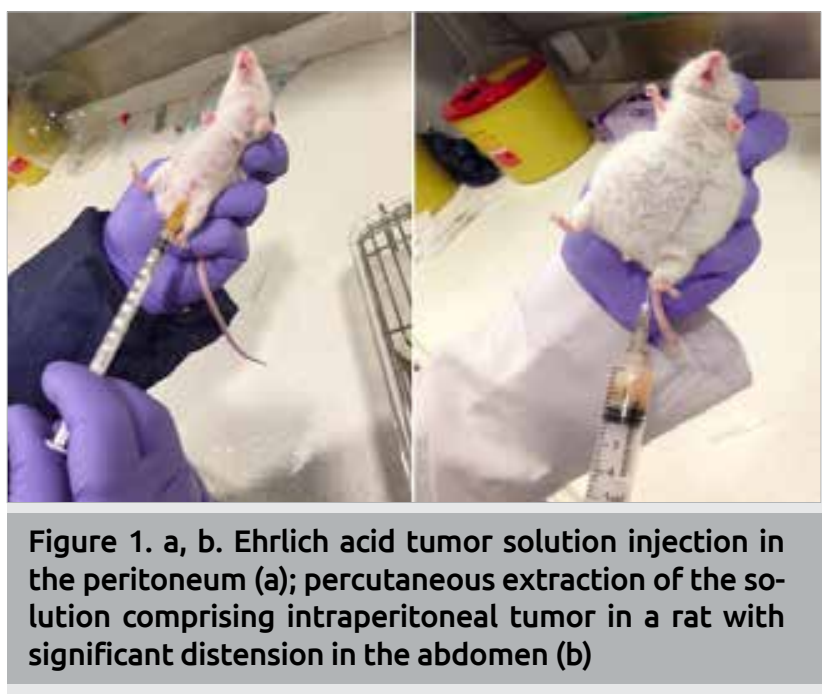




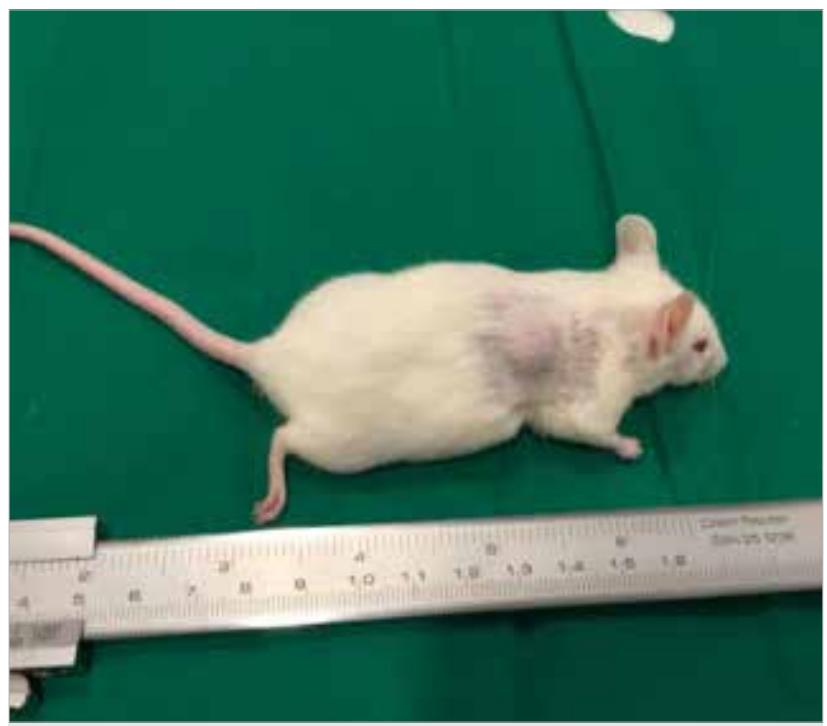

Figure 2. Image of experimental rat with tumor in subcutaneous region

USG screen images were recorded before and after the procedure. The HIFU device used was developed as a processor unit and a USG unit for clinical use in the treatment of prostate masses. The head of the USG device was ellipsoidal and $20 \mathrm{~mm}$ in the radial axis and $1,9 \mathrm{~mm}$ in the transverse direction. The duration of treatment was recorded in seconds.

Following the treatment procedure, tumor volumes were measured with USG over a 1-week period. For the determination of the treatment efficacy, pre- and post-treatment tumor diameter measurements (Diameter 1 and Diameter 12 for pre-treatment period and Diameter 21 and Diameter 22 for post-treatment period) and tumor volume calculations (Volume 1 for pre-treatment period and Volume 2 for post-treatment period) were made. For this, the two largest tumor diameters $(\mathrm{cm})$ were measured using a digital caliper. Using these values, calculations were made for preand post-treatment tumor volume [(diameter $\times$ diameter $) / 2$ $\left.\mathrm{cm}^{3}\right]$. At the end of the second week, the remaining tumor tissue was removed with at least $2 \mathrm{~mm}$ of the surrounding intact tissue immediately after the sacrification $(70 \mathrm{mg} / \mathrm{kg}$ ketamine), and it was transferred in formol to the pathology laboratory for histopathological examination. After paraffin blocks were prepared, the specimens transferred were evaluated under light microscopy using hemotoxylin-eosin dye to observe the presence and percentage of necrosis, tumor size, histological grade, growth type, and other features.

\section{Statistical Evaluation}

The data were processed using the Statistical Package for Social Sciences 12.0 (SPSS Inc., Chicago, IL, USA) program. Continuous variables were given as mean \pm standard deviation, and non-continuous variables as frequency and percentage. The Levene test was

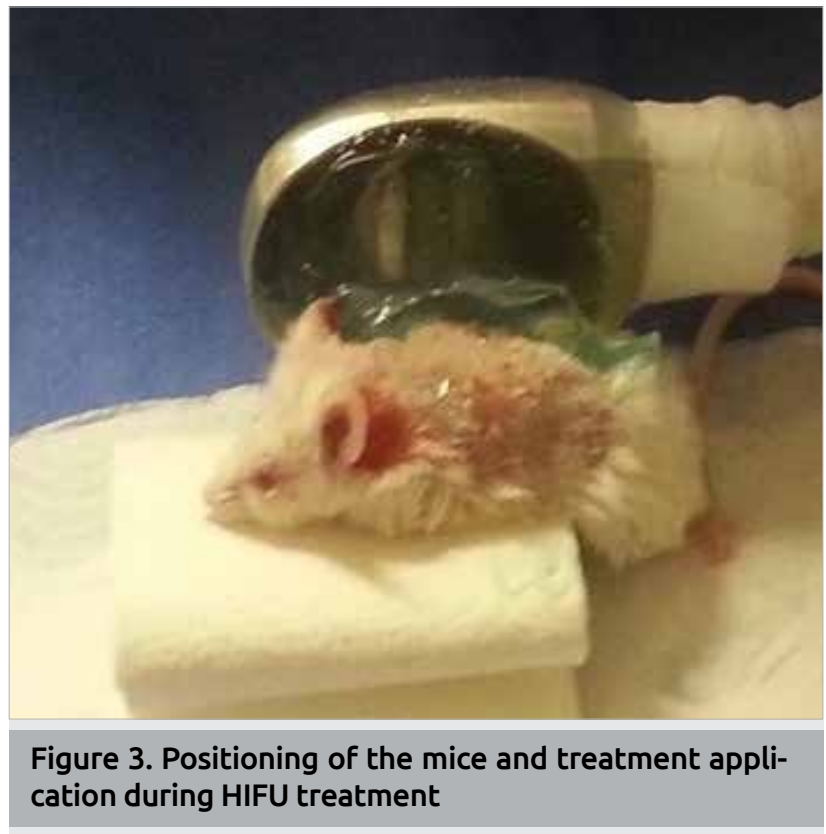

used to determine the homogeneity of group variances. In each group, t-test was performed to compare Volume 1 and Volume 2, which were two different variables in the group. For each group, significance between Volume 1 and Volume 2, intergroup significance for Volume 1, and intergroup significance for Volume 2 were specified. One-way ANOVA was used to compare the three groups in terms of Volume 1 and Volume 2 variables, and when a difference was detected, multiple comparisons were made with the post-hoc Tukey test to find out which group difference caused it. Comparisons were considered significant when p values were less than 0.05 with $95 \%$ confidence interval.

\section{Results}

After tumor formation in the subjects, the tumor diameters and volumes during the pre-treatment period and post-treatment changes of these tumors are summarized in Table 1. In the high-energy and low-frequency ultrasound group (Group 3 ), the mean duration of treatment was $26 \pm 2.82 \mathrm{~s}$.

All the excised tumors in all groups exhibited a macroscopically expansive growth pattern. Similarly, they were microscopically solid carcinoma with high histological grade (Figure 4). Tumor sizes and necrosis percentages are summarized in Table 2. There was no intergroup differences in terms of necrosis percentages $(p>0,05)$. In the high-energy and lowfrequency ultrasound group, sarcomatoid fusiform cell development was detected in one subject and partial connective tissue formation in five subjects.

For each group, the changes between Volume 2 and Volume 1 $[\Delta$ (Volume $2-$ Volume 1$)]$ were observed to be statistically significant $(\mathrm{p}=0.0001, \mathrm{p}=0.0001$, and $\mathrm{p}=0.006$ for each group, respectively). A significant difference was also found between Volume 2 and Volume 1 changes (Table 3). 
When Group 1 was considered as an independent variable for Volume 2, a statistically significant difference between the Volume 2 values of Groups 2 and 3 and those of Group 1 ( $\mathrm{p}=0.004$ and $\mathrm{p}=0.0001$, respectively; Table 4) was detected. When Group 2 was considered as an independent variable for $\Delta$ (Volume 2-Volume 1), statistically significant differences $(\mathrm{p}=0.005)$ between the Group $3 \Delta$ (Volume 2-Volume 1) and Group $1 \Delta$ (Volume 2-Volume 1) values were observed; similarly, when Group 1 was considered as an independent variable for $\Delta$ (Volume 2-Volume 1 ), statistically significant differences between the Group 2 and Group $3 \Delta$ (Volume 2-Volume 1) and Group $1 \Delta$ (Volume 2-Volume 1) values $(\mathrm{p}=0.003$ and $\mathrm{p}=0.0001$, respectively).

\section{Discussion}

In this study, we aimed to determine the effect of HIFU in a $\mathrm{Balb} / \mathrm{c}$ mice model in which subcutaneous tumor was formed with the Ehrlich acid tumor model. The results of this study revealed that HIFU treatment slowed down the growth of tumor and pathologic necrosis developed. after treatment

\begin{tabular}{|c|c|c|c|c|c|c|}
\hline Group & $\begin{array}{c}\text { Diameter } \\
11(\mathrm{~cm})\end{array}$ & $\begin{array}{l}\text { Diameter } \\
12(\mathrm{~cm})\end{array}$ & $\begin{array}{c}\text { Volume } 1 \\
\left(\mathrm{~cm}^{3}\right)\end{array}$ & $\begin{array}{c}\text { Diameter } \\
21(\mathrm{~cm})\end{array}$ & $\begin{array}{l}\text { Diameter } \\
22(\mathrm{~cm})\end{array}$ & $\begin{array}{c}\text { Volume } 2 \\
\left(\mathrm{~cm}^{3}\right)\end{array}$ \\
\hline Group & $11.22 \pm 0.19$ & $0.54 \pm 0.06$ & $0.16 \pm 0.02$ & $1.47 \pm 0.18$ & $0.75 \pm 0.07$ & $0.30 \pm 0.05$ \\
\hline Group & $21.37 \pm 0.06$ & $0.48 \pm 0.04$ & $0.18 \pm 0.03$ & $1.58 \pm 0.06$ & $0.61 \pm 0.05$ & $0.40 \pm 0.06$ \\
\hline Group & $31.24 \pm 0.18$ & $0.51 \pm 0.07$ & $0.17 \pm 0.04$ & $1.33 \pm 0.04$ & $0.6 \pm 0.08$ & $0.23 \pm 0.06$ \\
\hline
\end{tabular}

Table 2. Histopathological evaluation results

\begin{tabular}{|c|c|c|}
\hline & Size (cm) & Necrosis (\%) \\
\hline Group 1 & $2.38 \pm 0.35$ & $70 \pm 9.4$ \\
\hline Group 2 & $2.44 \pm 0.56$ & $70 \pm 9.6$ \\
\hline Group 3 & $2.13 \pm 0.51$ & $75.6 \pm 4.17$ \\
\hline
\end{tabular}

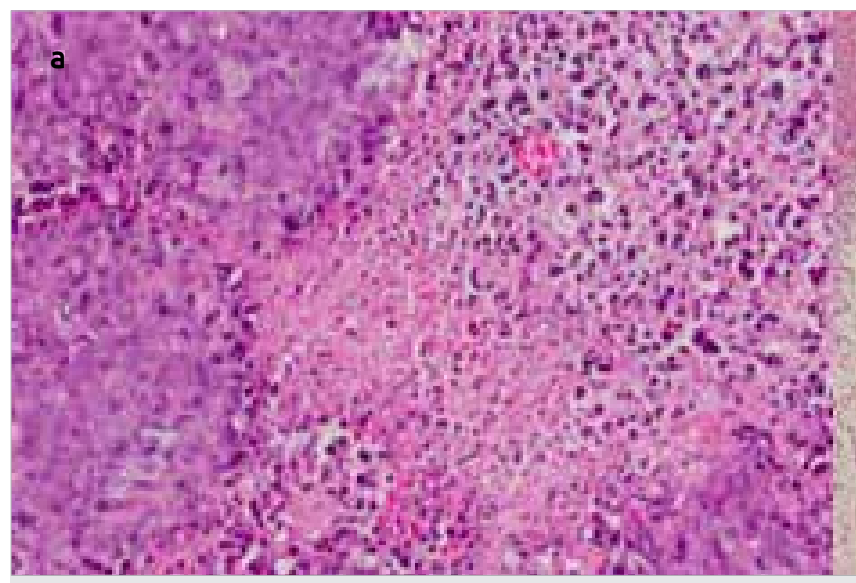

Table 1. Tumor diameter and volume values before and

The models of colon and pancreatic adenocarcinoma cells were especially used in the experimental studies conducted on HIFU in the literature $(2,14,18)$. However, in this study, it was not possible to obtain a solid tumor as a result of the inoculation performed using the colon cancer cell line [HT$29\left(\mathrm{HTB}-38^{\mathrm{TM}}\right)$ ]. Therefore, the study was performed with the Ehrlich acid tumor model. To the best of our knowledge, there is no study about the use of HIFU in the Ehrlich acid tumor model. Therefore, this is the first report demonstrating the use of HIFU based on this cell model.

In recent years, in addition to diagnostic procedures, USG technology has become increasingly widespread for use in

\begin{tabular}{lcc}
\hline Table 3. ANOVA analysis & & \\
& F & P \\
\hline Volume 1 & 0.819 & 0.454 \\
Volume 2 & 19.126 & 0.0001 \\
\hline (Volume 2-Volume 1) & 26.572 & 0.0001 \\
\hline ANOVA: analysis of variance & & \\
\hline
\end{tabular}

\begin{tabular}{l|l|c|c|}
\hline \multicolumn{3}{l}{$\begin{array}{l}\text { Table 4. Intergroup significance analysis with post-hoc } \\
\text { Tukey HSD test }\end{array}$} & P \\
\hline Parameter & Independent variable & Group 2 & 0.004 \\
\hline Volume 2 & Group 1 & Group 3 & 0.051 \\
& Group 2 & Group 1 & 0.004 \\
\hline & & Group 3 & 0.0001 \\
\hline (volume & Group 1 & Group 2 & 0.003 \\
\hline 2-volume 1) & & Group 3 & 0.005 \\
& Group 2 & Group 1 & 0.003 \\
\hline HSD: honest significant difference & Group 3 & 0.0001 \\
\hline
\end{tabular}

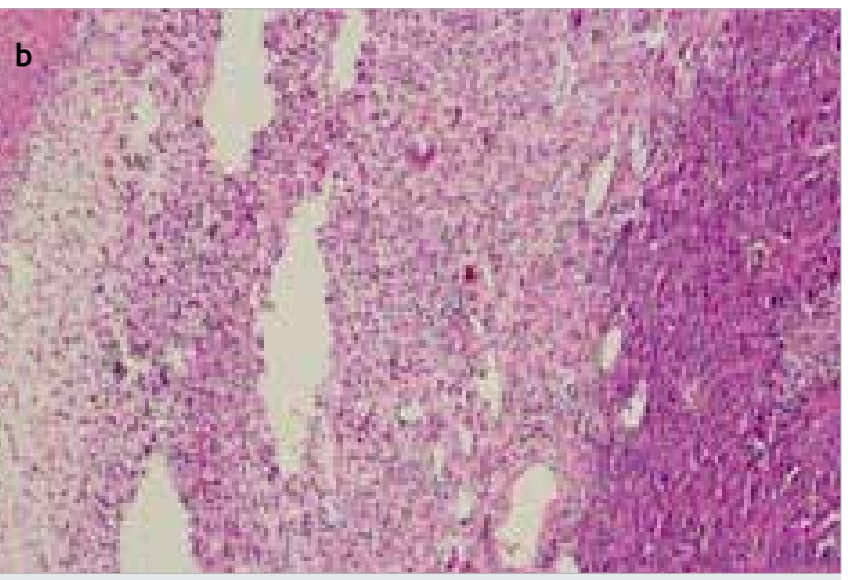

Figure 4. a, b. High-grade solid carcinoma and necrosis area (H \& E400x) (a); on the top-left, diffuse necrosis area (H \& E 100x) with connective tissue formation in the center (b) 
the treatment of tumors with various pathological features. Within this context, there are experimental and clinical applications in which HIFU has been used, especially in small solid tumors (2). Such treatments can be used as part of radical surgery as well as for palliative purposes. Nevertheless, the biological effects of USG waves on malignant tissues remain under investigation. Although the biological responses of non-malignant tissues to USG energy may differ, studies have demonstrated that cancerous tissues and cells are relatively more sensitive, that cell proliferation and colon tumor formation can be inhibited with treatment, and that the effect of chemotherapeutic drugs can be increased $(19,20)$. In this study; however, the effect of HIFU on normal tissues was not studied; its effect was studied only on cancerous tissues. Therefore, it was not possible to make a comparison between the effect of HIFU on normal and cancerous tissues with the data obtained from the study.

Heat, mechanical interaction, and acoustic cavitation are among the biological effects that are observed when cancerous tissues are confronted with USG energy (2); among these, acoustic cavitation is considered the most effective (21). Short-time high temperature and high pressure, which are liberated in the collapsed tissues, lead to the formation of air droplets and continuous increase in pressure. The pathological events that occur during this time period results in the conversion of sound energy to light energy, which is defined as "sonoluminescence," and this phenomenon can be observed under USG. When HIFU was used in the study, the continuation of treatment until tumorous tissues became hyperechoic is based on this mechanism (18). During the experiment, a characteristic appearance under USG was obtained in subjects who underwent HIFU treatment. Therefore, the use of diagnostic USG during the procedure is an important adjunct $(22,23)$.

Studies in the literature demonstrated that significant decreases in tumor volume were detected in groups treated with HIFU whereas tumor growth continued in control and sham groups $(15,24,25)$. In this study, tumor growth continued in control, sham, and HIFU treatment groups. The statistically significant difference between Volume 1 and Volume 2 values in control (Group 1) and sham (Group 2) groups suggests that tumors continue to grow, if not treated. There was no statistically significant difference between the pre-treatment (Volume 1) and post-treatment (Volume 2) values in the HIFU treatment group (Group 3). Considering Group 1 and Group 2, although there is an increase in Volume 2 in comparison to Volume 1 for Group 3, it can be inferred that there is a significant effect as a numerical value. There is an increase of $87.5 \%$ and $122.2 \%$ for Group 1 and Group 2, respectively, in the tumor volume considering the average value, whereas this increase rate is $35.3 \%$ for Group 3. Previous studies have demonstrated that the combined use of therapeutic USG reduced tumor growth in the Ehrlich acid model $(15,17)$. Therefore, it may be possible to effectively decrease tumor volume or to completely remove the tumor tissue using appropriate technical features.

In the triple analysis performed with ANOVA variance analysis, it was concluded that there are significant differences in the change of Volume 2 and $\Delta$ (Volume 2-Volume 1) values. In the post-hoc Tukey test conducted to determine which group difference caused this, it was concluded that the Volume 2 value of Group 3 was significantly lower than that of Group 2. However, no statistical difference was found between the Volume 2 values of Group 1 and Group 3. Therefore, the effect of HIFU treatment on tumor volume was significant only according to the sham group. However, when $\Delta$ (Volume $2-$ Volume 1$)$ is examined, and when Group 1 and Group 2 are considered as independent variables, $\Delta$ (Volume 2 -Volume 1 ), which is valid for Group 3 , is statistically significant. According to this $\Delta$ (Volume 2-Volume 1) value, a significant effect of HIFU on tumor volume change was demonstrated compared with that for sham and control groups. Therefore, it was concluded that HIFU had a reducing effect on the increase in tumor volume. To provide a reduction in tumor volume, technical regulations related to the duration of HIFU may be considered necessary. Experimental models are needed to demonstrate that there are technical differences associated with this duration.

Some studies suggest that light microscopy may not be sufficient in determining necrosis, so electron microscopy may be required (18). Although it is shown that HIFU-induced cell death is mostly caused by necrosis resulting from heat, apoptosis is considered to be the primary mechanism responsible for cell death in necrosis due to hyperthermia (26). In the study, only necrosis was concentrated on in the subjects, and detailed pathologic examination including apoptosis could not be performed because necrotic tissue covered most of the specimens. It is considered that waiting until the tumor diameter reaches $5-6 \mathrm{~mm}$ is effective on necrosis development, which was observed in the subjects of control, sham, and HIFU treatment groups. In cases where tumor growth continues, necrotic areas may be expected to develop due to the lack of sufficient vascularization. When the treatment group was compared with other groups to find the cause of necrosis, the formation of connective tissue was observed only in the treatment group. Hence, such pathological changes being only in the treatment group were considered to be in favor of the fact that HIFU had a pathological effect. The connective tissue formation observed in the treatment group is evaluated to be mostly related to the necrotic tissue being resorbed, abscess formation, calcification development, and regeneration process. Therefore, it can be inferred that such changes in the treatment group are secondary to the necrosis caused by the thermal or mechanical effect of HIFU. 


\section{Conclusion}

In the light of the data obtained in the study, considering tumor volume and histopathological features, it can be considered that partial response to HIFU treatment was obtained in Balb/c mice in which Ehrlich tumor was established. It is considered that increasing the duration of treatment, repeated treatment within a few days, or starting the treatment early in the course of tumor formation is effective in obtaining complete response to HIFU treatment.

Ethics Committee Approval: Ethics committee approval was received for this study from the Experimental Animals Application and Research Center of Bezmialem Vakıf University.

Peer-review: Externally peer-reviewed.

Author Contributions: Concept - G.Ç., T.K.; Design - G.Ç., M.H.; Supervision - M.H.; Resources - M.H., T.K.; Materials Z.G., R.S.; Data Collection and/or Processing - T.K., Ö.O., M.H.; Analysis and/or Interpretation - Z.G., M.H.; Literature Search M.H., Ö.O.; Writing Manuscript - M.H., T.K.; Critical Review - M.M., S.K.

Conflict of Interest: No conflict of interest was declared by the authors.

Financial Disclosure: This study was financially supported by the TÜBİTAK within the scope of 3001 program (Project No: 213S104)

\section{References}

1. Monzon L, Wasan H, Leen E, Ahmed H, Dawson PM, Harvey C, et al. Transrectal high-intensity focused ultrasonography is feasible as a new therapeutic option for advanced recurrent rectal cancer: report on the first case worldwide. Ann R Coll Surg England 2011; 93: e119-21. [CrossRef]

2. Sazgarnia A, Shanei A, Taheri AR, Meibodi NT, Eshghi H, At$\operatorname{taran} \mathrm{N}$, et al. Therapeutic effects of acoustic cavitation in the presence of gold nanoparticles on a colon tumor model. J Ultrasound Med 2013; 32: 475-83. [CrossRef]

3. Dubinsky TJ, Cuevas C, Dighe MK, Kolokythas O, Hwang JH. High intensity focused ultrasound: current potential and oncologic applications. Am J Roentgenol 2008; 190: 191-9. [CrossRef]

4. Kennedy JE, Ter Haar GR, Cranston D. High intensity focused ultrasound: surgery of the future. Br J Radiol 2003; 76: 590-9. [CrossRef]

5. Maestroni U, Ziveri M, Azzolini N, Dinale F, Ziglioli F, Campaniello G,et al. High Intensity Focused Ultrasound (HIFU): a useful alternativechoice in prostate cancer treatment. Preliminary results. Acta Biomed 2008; 79: 211-6.

6. Blana A, Rogenhofer S, Ganzer R, Lunz JC, Schostak M, Wieland WF, et al. Eight years experience with high intensity focused ultrasonography for treatment of localized prostate cancer. Urology 2008; 72: 1329-33. [CrossRef]

7. Wu F, Wang ZB, Cao YD, Chen WZ, Bai J, Zou JZ, et al. A randomised clinical trial of high intensity focused ultrasound ablation for the treatment of patients with localised breast cancer. Br J Cancer 2003; 89: 2227-33. [CrossRef]

8. Wu F, Wang ZB, Zhu H, Chen WZ, Zou JZ, Bai J, et al. Extracorporeal high intensity focused ultrasound treatment for patients with breast cancer. Breast Cancer Res Treat 2005; 92: 51-60. [CrossRef]

9. Roussanka D Kovatcheva, Jordan D Vlahov, Julian I Stoinov, Katja Zaletel. Benign Solid Thyroid Nodules: US-guided HighIntensity Focused Ultrasound Ablation Initial Clinical Outcomes. Radiology 2015; 276: 597-605. [CrossRef]

10. Zhu J, Zhu H, Mei Z, Jin C, Ran L, Zhou K, et al. High-intensity focused ultrasound ablation for treatment of hepatocellular carcinoma and hypersplenism: preliminary study. J Ultrasound Med 2013; 32, 1855-62.

11. Klingler HC, Susani M, Seip R, Mauermann J, Sanghvi N, Marberger MJ. A novel approach to energy ablative therapy of small renal tumours: laparoscopic high intensity focused ultrasound. Eur Urol 2008; 53: 810-8. [CrossRef]

12. Chan AH, Fujimoto VY, Moore DE, Martin RW, Vaezy S. An image-guided high intensity focused ultrasound device for uterine fibroids treatment. Med Phys 2002; 29: 2611-20. [CrossRef]

13. Fruehauf JH, Back W, Eiermann A, Lang MC, Pessel M, Marlinghaus E, et all. High intensity focused ultrasound for the targeted destruction of uterine tissues: experiences from a pilot study using a mobile HIFU unit. Arch Gynecol Obstet 2008; 277: 143-50. [CrossRef]

14. Park MJ, Kim YS, Yang J, Sun WC, Park H, Chae SY, et al. Pulsed high intensity focused ultrasound therapy enhances targeted delivery of cetuximab to colon cancer xenograft model in mice. Ultrasound Med Biol 2013; 39: 292-9. [CrossRef]

15. Mohamed MM, Mohamed MA, Fikry NM. Enhancement of antitumor effects of 5-fluorouracil combined with ultrasound on Ehrlich ascites tumor in vivo. Ultrasound Med Biol 2003; 29: 1635-43. [CrossRef]

16. Hao Q, Liu Q, Wang X, Wang P, Li T, Tong WY. Membrane damage effect of therapeutic ultrasound on Ehrlich ascitic tumor cells. Cancer Biother Radiopharm 2009; 24: 41-8. [CrossRef]

17. Ghosh P, Sur P, Bag SP. Enhancement of antitumor effects of a new boron compound combined with ultrasound on the mouse ascites tumor. Med Chem 2012; 8: 1026-31. [CrossRef]

18. Lixin Jiang, Bing Hu, Qian Guo, Li Chen. Treatment of pancreatic cancer in a nude mouse model using high-intensity focused ultrasound. Exp Ther Med 2013; 5: 39-44. [CrossRef]

19. Hrazdira I, Skorikova J, Dolnikova M. Ultrasonically induced alterations of cultured tumor cells. Eur J Ultrasound 1999; 8: 43-9. [CrossRef]

20. Yu T, Wang Z, Jiang S. Potentiation of cytotoxicity of adriamycin on human ovarian carcinoma cell line $3 \mathrm{AO}$ by low level ultrasound. Ultrasonics 2001; 39: 307-9. [CrossRef]

21. Marmottant P, Hilgenfeldt S. Controlled vesicle deformation and lysis by single oscillating bubbles. Nature 2003; 423: 1536. [CrossRef]

22. Miyoshi N, Igarashi T, Rieze P. Evidence against singlet oxygen formation by sonolysis of aqueous oxygen-saturated solutions of hematopor- phyrin and rose Bengal: the mechanism of sonodynamic therapy. Ultrason Sonochem 2000; 7: 121-4. [CrossRef] 
23. Miyoshi N, Sostsric JZ, Rieze P. Correlation between sonochemistry of surfactant solution and human leukemia cell killing by ultrasound and porphyrins. Ultrasound Med Biol 2003; 34: 710-9. [CrossRef]

24. Keshavarzi A, Vaezy S, Noble ML, Chi EY, Walker C, Martin $\mathrm{RW}$, et all. Treatment of uterine leiomyosarcoma in a xenograft nude mouse model using high intensity focused ultrasound: a potential treatment modality for recurrent pelvic disease. Gynecol Oncol 2002; 86: 344-50. [CrossRef]
25. Vaezy S, Fujimoto VY, Walker C, Martin RW, Chi EY and Crum LA. Treatment of uterine broid tumours in a nude mouse model using high-intensity focused ultrasound. Am J Obstet Gynecol 2000; 183: 6-11. [CrossRef]

26. Vykhodtseva N, McDannold N, Martin H, Bronson RT and Hynynen K. Apoptosis in ultrasound produced threshold lesions in the rabbit brain. Ultrasound Med Biol 2001; 27: 1117. [CrossRef] 